\title{
Editorial: Technology in higher education and human performance
}

\section{Minhong Wang*}

Faculty of Education

The University of Hong Kong, Hong Kong

E-mail: magwang@hku.hk

\section{Chi-Cheng Chang}

Department of Technology Application and Human Resource Development National Taiwan Normal University, Taiwan

E-mail: samchang@ntnu.edu.tw

*Corresponding author

\begin{abstract}
Improvement of learning and human development for sustainable development has been recognized as a key strategy for individuals and organizations to strengthen their competitive advantages. It becomes crucial to help adult learners and knowledge workers to improve their self-directed and life-long learning capabilities. Meanwhile, learning in this context has expanded from individual to community and organizational levels with new focuses on externalization of tacit knowledge, creation of new knowledge, retention of knowledge assets for continuous improvement, and cross-cultural communication. To adapt to these changes, technologies have played an increasingly important role in enhancing and transforming learning at individual, community, and organizational levels. Papers in this special issue are representative of ongoing research on integration of technology with learning for innovation and sustainable development in higher education institutions and organizational and community environments.
\end{abstract}

Keywords: Educational technology; Higher education; Human development

Biographical notes: Dr. Maggie Minhong Wang is an Associate Professor in the Faculty of Education, The University of Hong Kong. She has been involved in multiple disciplinary research in the areas of technology-enhanced learning, complex problem solving and learning, knowledge management, adult learning and human performance, and artificial intelligence. She has published papers in Computers \& Education, Information \& Management, IEEE Transactions on Education, Educational Technology \& Society, Innovations in Education \& Teaching International, Expert Systems with Applications, Knowledge-based Systems, Journal of Knowledge Management, among others. She is the Editorin-Chief of Knowledge Management and E-Learning: an International Journal. She also serves on the editorial board of several international journals including Educational Technology Research and Development, and Educational Technology \& Society. More details can be found at http://web3.edu.hku.hk/magwang/.

Dr. Chi-Cheng Chang is a distinguished professor and the Chairperson in the Department of Technological Application and Human Resource Development, National Taiwan Normal University. He gained his $\mathrm{PhD}$ in Workforce 
Education and Development from the Pennsylvania State University, USA. His research interests are focused on e-learning strategies and digital assessment. He has published many papers in the SSCI journals. He is now the president of Association of Taiwan Engineering Education and Management (ATEEM), the national representative in International Federal of Engineering Education Society (IFEES), and the Secretary General of Taiwanese Association of Industrial Technology Education. He also serves on the Editor-in-Chief of Taiwan Journal of Technology and Technology Education, Associated Editors of International Journal of Technology and Engineering Education as well as Instructional Technology and Media.

\section{Introduction}

Globalization and economic dynamics have forced individuals and organizations to search for new ways to strengthen their competitive advantages. Against this background, improvement of learning and human performance for sustainable development has been recognized as a key strategy. In this context, it is crucial to help adult learners and knowledge workers to improve their self-directed and life-long learning capabilities for innovation and sustainable development (Wang \&Yang, 2009). Meanwhile, learning in this context has expanded from individual to community and organizational levels with new focuses on externalization of tacit knowledge, creation of new knowledge, retention of knowledge assets for continuous improvement, and cross-cultural communication. To adapt to these changes, technologies have played an increasingly important role in enhancing learning, and professional development, especially in the digital economy. While moving from technology-enhanced learning to technology-transformed learning, there is a high demand for more extensive and intensive research on how technology can be integrated with learning and performance in various aspects (Ge, 2011; Kushniruk, 2011; Wang, Vogel, \& Ran, 2011).

The papers in this special issue are intended to be representative of ongoing research with practical implementations and evaluations of emerging technologies in higher education and human development, with an international scope.

\section{Preview of papers}

In the first paper "Learning Analytics as a Tool for Closing the Assessment Loop in Higher Education", Karen D. Mattingly, Margaret C. Rice, and Zane L. Berge discuss learning and academic analytics and its relevance to distance education in undergraduate and graduate programs. The paper presents the integration of collection and analysis of data from a variety of sources, such as learning management systems and social networking and cloud-based platforms, to allow individuals and institutions to make informed decisions about allocating resources and enabling interventions that promote successful learning strategies.

Learning through problem solving has been increasingly used as an effective approach to learning and expertise development, especially in challenging domains such as medical education. However, the effect of problem solving on learners' coherent knowledge structure or systemic understanding remains unsatisfactory. The 2 nd paper "Integrating problem solving and knowledge construction through dual mapping" by 
Bian Wu and Minhong Wang addresses the challenge by the design of a dual mapping cognitive tool to support medical diagnostic problem solving and knowledge construction, together with a preliminary evaluation on the effect of the designed tool.

Learning with games, simulations, and virtual worlds have been widely adopted to foster immersive learning and in-depth understanding of complex topics. Jenny S. Wakefield, Scott J. Warren, Monica A. Rankin, Leila A. Mills, and Jonathan S. Gratch present the design of a higher education history course using the Second Life role play for an assignment, in their paper "Learning and teaching as communicative actions (LTCA)." The design is informed by the LTCA framework, in which communication and discourse, and the interplay among four communicative actions form the basis of human understanding.

The 4th paper "Impact of clicker technology in a mathematics course" by Sibongile Simelane and Phindile Maria Skhosana introduces the implementation of clicker technology in a first-year mathematics course in a university of South Africa. Clicker technology has been used to make students motivated and engaged in classroom activities, via measuring student understanding and providing immediate feedback. The study reported the impact of click technology on improving learners' engagement, interaction, and learning outcome.

Building knowledge bases and increasing opportunities for continuous learning are recognized as crucial to strengthen the global workforce and health systems. Lisa Mwaikambo, Megan Avila, Sara Mazursky, and Kavitha Nallathambi investigate the utilization of e-learning to improve the capacity of health practitioners and regional and local nongovernmental organizations in developing countries. Their study presents the success of the Global Health eLearning (GHeL) Center and the findings from a multiphased evaluation of the Knowledge for Health (K4Health) Project, based at Johns Hopkins Bloomberg School of Public Health's Center for Communication Programs (JHU·CCP).

The integration of e-learning into the higher education system is becoming increasingly popular in many countries. The 6th paper by Ijaz A. Qureshi, Khola Ilyas, Robina Yasmin, and Michael Whitty discusses the integration of e-learning into a teaching program in a private university in Pakistan. The findings indicate that electricity failure and English proficiency are the most significant barriers to successful integration of e-learning, in addition to other issues such as absence of security and antivirus software for computers, proper working environment, and full time staff for technical assistance.

In the 7th paper, Bridget K. Welch and Jess Bonnan-White examine the effect of Twitter on student engagement in a university classroom. No significant difference was found in any form of engagement when Twitter was part of the course than when it was not. Students who reported enjoying using Twitter were found more engaged than those who did not enjoy Twitter. The findings suggest that the most important step to increasing student engagement through multiple channels of communication is to allow students to drive social media selection.

Multimedia with hypertext, interactive simulations, and animation systems has been intensively used for effective information delivery and interactive teaching and learning. Hsiu-Ping Yueh, Weijane Lin, Jo-Yi Huang, and Horn-Jiunn Sheen investigate the use and effect of multimedia in an engineering and technology course in a university of Taiwan. Their findings indicate that multimedia videos help to raise students' awareness of learning issues and improve their understanding of content, and that 
students' degree of learning engagement influences their perception of the helpfulness of multimedia-assisted learning.

While e-learning has been increasingly adopted by companies to overcome time and space constraints in delivering training programs, the success rate of e-learning implementation in real practice is found to be low. In the 9th paper "The impact of employee's perception of organizational climate on their technology acceptance toward e-learning in South Korea", Sun Joo Yoo, Wen-Hao Huang, and Da Ye Lee explore the influence of perceived organizational climate on employees' acceptance of e-learning in a regional food service company in South Korea.

The acceleration of digital technology development requires people to be equipped with skills and literacies to survive in the information age. In the last paper, MayLin Yen presents the construction and analysis of indicators of college students' information ability for employability. This study investigates the skills for employability expected of college students in Taiwan, with a view to helping students to understand their current abilities and providing a reference for schools to develop courses for integrating information skills with employment abilities.

\section{Conclusions}

This special issue provides a forum for academics and practitioners to draw attention to recent research on technology in higher education and human development. The international scope of these studies is distinctive. The breadth of applications discussed in these papers is important. We hope that this special issue will foster further interest in what we believe will become an area of increasing importance, as new technologies are developed and their efficacy explored to support and transform learning for innovative and sustainable development at individual, community, and organizational levels.

\section{Acknowledgements}

The guest editors would thank the Chairs and Organizers of the 15th Global Chinese Conference on Computers in Education (GCCCE) for their warm support of this special issue. Two papers (Wu \& Wang; Yen) of the special issue were selected from this conference under the theme "Technology in Higher Education and Human Performance", in addition to others received from an open call for this special issue. 


\section{References}

Ge, X. (2011). Editorial: Creating, supporting, sustaining and evaluating virtual learning communities. Knowledge Management \& E-Learning: An International Journal, 3(4), 507-512.

Kushniruk, A. W. (2011). Editorial: Advances in health education applying e-learning, simulations and distance technologies. Knowledge Management \& E-Learning: An International Journal, 3(1), 1-4.

Wang, M., Vogel, D., \& Ran, W. (2011). Creating a performance-oriented e-learning environment: A design science approach. Information \& Management, 48(7), 260269.

Wang, M., \& Yang, S. J. H. (2009). Editorial: Knowledge management and e-learning. Knowledge Management \& E-Learning: An International Journal, 1(1), 1-5. 